\title{
Nanotechnology, an alternative with promising prospects and advantages for the treatment of cardiovascular diseases
}

This article was published in the following Dove Press journal: International Journal of Nanomedicine

\section{Tao Li* \\ Weitao Liang* \\ Xijun Xiao \\ Yongjun Qian}

Department of Cardiovascular Surgery, West China Hospital, Sichuan University, Chengdu, China

*These authors contributed equally to this work
Correspondence: Yongjun Qian Department of Cardiovascular Surgery, West China Hospital, Sichuan University, No. 37, Guoxue Lane, Wuhou District, Chengdu, Sichuan, China

Tel +862885422897

Fax $+86288542 \quad 1833$

Email qianyongjun@scu.edu.cn

\begin{abstract}
Cardiovascular diseases (CVDs) are one of the most important causes of mortality and affecting the health status of patients. At the same time, CVDs cause a huge health and economic burden to the whole world. Although a variety of therapeutic drugs and measures have been produced to delay the progress of the disease and improve the quality of life of patients, most of the traditional therapeutic strategies can only cure the symptoms and cannot repair or regenerate the damaged ischemic myocardium. In addition, they may bring some unpleasant side effects. Therefore, it is vital to find and explore new technologies and drugs to solve the shortcomings of conventional treatments. Nanotechnology is a new way of using and manipulating the matter at the molecular scale, whose functional organization is measured in nanometers. Because nanoscale phenomena play an important role in cell signal transduction, enzyme action and cell cycle, nanotechnology is closely related to medical research. The application of nanotechnology in the field of medicine provides an alternative and novel direction for the treatment of CVDs, and shows excellent performance in the field of targeted drug therapy and the development of biomaterials. This review will briefly introduce the latest applications of nanotechnology in the diagnosis and treatment of common CVDs.
\end{abstract}

Keywords: nanotechnology, application, targeted therapy, biomaterials, cardiovascular diseases

\section{Introduction}

Nanotechnology is a new way of using and manipulating the matter at the molecular scale, whose functional organization is measured in nanometers. ${ }^{1}$ Feynman, ${ }^{2}$ a charismatic, imaginative and witty leader, suggested to people that there are no physical barriers to manipulate individual atoms and molecules, and inspired the development of nanotechnology in his lecture entitled "There's Plenty of room at bottom", a profound insight of nanotechnology in 1950s. Smalley et al ${ }^{3}$ elucidated the structure of nano-macromolecule fullerene, elegant and perfect structure with unique performances, which has attracted intense interest from scientists in exploring other nanomolecular structures. Past decades have witnessed a growth explosion in an attractive field of nanotechnology. ${ }^{4}$

As nanoscale phenomena play an important role in cell signal transduction, enzyme action and cell cycle, nanotechnology is closely related to medical research. Nanotechnology provides a tool for structural analysis at the most important dimensions of organizational structure, atomic and cellular levels, and designs and manufactures synthetic biomaterials on a nanoscale with new treatments and alternative materials emerging. Nanotechnology proposes a biological approach that uses precisely targeted 
nanopharmaceuticals to bind proteins and nucleic acids associated with disease and dysfunction. Nanotechnology also provides tools and techniques for transferring fine organic macromolecules and peptides to the places where they exert effects, protecting them from degradation and immune rejection, and making them cross barriers that prevent macromolecules from passing through them. ${ }^{5}$

Medical nanotechnology has shown an increasing trend in reducing costs and improving the effectiveness of existing drugs, diagnostic reagents, implants, prostheses, patient monitors and individual health care. The actual impact of nanotechnology mainly includes the following aspects: ${ }^{5}$ advanced medical instruments, system biology and therapeutic diagnostic technology, realization of distributed individualized nursing, medical materials, nanoparticles (NPs) for image enhancement, drug delivery, overcoming the natural barrier of drug delivery, implanted immune protection system, advanced restorative science, advanced biosensors and implants for treatment, and defense against disease transmission.

Cardiovascular diseases (CVDs), such as acute myocardial infarction (AMI), hypertension, atherosclerosis, stroke and heart failure, among others, are one of the most hazardous and deadliest diseases, producing stupendous health and economic burdens in the all of the world. ${ }^{6}$

CVDs are the group of pathological disorders that occur in cardiac, valvular and blood vessel tissues associated with heart. In response to various pathological disorders, a variety of therapeutic drugs and measures have been born, contributing to improve the patients' quality of life. However, conventional treatment strategies are not allowed to repair or regenerate damaged ischemic myocardium. Moreover, the use of agents frequently brings about systemic certain side effects. Therefore, these facts force researchers to conduct a variety of studies to find more effective and safer treatments and drugs. ${ }^{7-9}$

Although there have been several reviews about the application of nanotechnology in CVDs, advances in knowledge and technology are changing rapidly. Moreover, most of the other related reviews focused on the application of nanotechnology to a single disease category, giving readers a deeper understanding of the future of nanotechnology in one aspect. And, this review describes the application of nanotechnology in several common CVDs, not only in depth but also in scope, to make readers understand the application of nanotechnology in CVDs, causing the diffusion of readers' thinking, to stimulate the research of nanotechnology in more fields and promote the development of nanotechnology. This review will provide a more comprehensive description of the latest advances in the cardiovascular field of NPs. In this review, we call on implementing nanotechnology as a promising and innovative orientation for the treatment of CVDs.

\section{Roles of NPs in CVDs}

Owing to their unique size, physical properties and chemical composition, NPs are able to deliver targeted drugs through blood and tissue flow. It can also be cleared in tissues and organs long enough to enhance imaging or perform other unique nanoscale functions. Hence, NPs are mainly used for enhanced medical imaging, targeted delivery to kill pathological cells, and targeted delivery of drugs. ${ }^{10}$

\section{NPs in diagnosis and treatment of coronary artery disease (CAD)}

$\mathrm{CAD}$ is the process of atherosclerotic plaque gathering on the inner wall of the coronary artery, causing the stenosis of the cavity, reducing the compliance of the vascular wall, and gradually or abruptly causing the loss of the blood supply of partial myocardium. ${ }^{11}$ Atherosclerosis is a chronic disease characterized by thickening of the arterial wall and inflammation of atherosclerotic plaques. ${ }^{12} \mathrm{~A}$ heart attack would occur with coronary arteries blocked completely by atherosclerosis. During this process, hypoxia of cardiomyocytes (CMs) triggers a series of complex and interrelated physiological responses involving various cells, cytokines and extracellular matrix (ECM). All of these processes lead to the loss of cardiac function, accompanied by fibrous scars to replace the myocardium. ${ }^{7}$

The most frequent cause of coronary thrombosis is the shedding or rupture of the atherosclerotic plaque. ${ }^{13}$ The plaques, called as "vulnerable", are apt to rupture due to certain characteristics, involving the appearance of multitudinous inflammatory cells and a large necrotic core with a flimsy fibrous cap, reduced smooth muscle cells (SMCs), and a decreased ECM, plaque bleeding and calcification, among others. ${ }^{14}$

At present, the common diagnostic methods of CAD are electrocardiography (ECG), stress echocardiography, coronary computed tomography angiography, coronary angiography (CAG) and MRI. However, these conventional methods do not identify such "vulnerable plaques." 15,16 With the improvement of diagnostic requirements and technologies, molecular imaging of CVDs based on nanotechnology is emerging to detect certain targets, such as macrophages, oxidized low-density lipoprotein (oxLDL), microvessels, etc. ${ }^{17}$ 
Aikawa et $\mathrm{al}^{18}$ used a cross-linked iron oxide fluorescent NP to simultaneously image macrophages for determination of inflammatory response in atherosclerotic plaques. ${ }^{18}$ Due to the absence of fluorine $\left({ }^{19} \mathrm{~F}\right)$ background in targeted tissue, observed signals of ${ }^{19} \mathrm{~F}$ perfluorocarbons NPs from MRI permit a spatial resolution and a fine specificity to demonstrate inflammation progress. ${ }^{19}$ In addition, the combined utilization of intravascular ultrasound and photoacoustic (IVUS/IVPA) imaging with gold NPs as contrast agents to co-localize with active macrophages in plaques as described by Yeager et al. ${ }^{20}$ Therefore, the progression and fragility of atherosclerotic plaques can be judged by detecting the content, infiltration and proliferation of macrophages.

Apoptosis and oxLDL play an important role in triggering and promoting plaque rupture. Various approaches, such as agents labeled with radioisotopes $\left({ }^{123} \mathrm{I},{ }^{124} \mathrm{I},{ }^{99 \mathrm{~m}} \mathrm{Tc}\right.$, and $\left.{ }^{18} \mathrm{~F}\right)$ and superparamagnetic particles (iron oxide and gadolinium) for positron emission tomography (PET), single-photon emission computed tomography, or MRI, have come to the fore to image certain targets associated with apoptosis and oxLDL in demarcating plaques in risk for rupture. ${ }^{21-23}$

Microvessels at the bottom of atherosclerotic plaque independently associated with plaque rupture, suggesting a contributory role for neo-vessel generation in the process of plaque growth, hemorrhage and rupture. ${ }^{24}$ Integrin $\alpha v \beta 3$, a key mediator of angiogenesis, has been targeted by using a gadolinium-coated perfluorocarbon nanomaterial (containing 90,000 separate gadolinium chelates) derivatized with an arginine-glycine-aspartic acid peptidomimetic. ${ }^{25}$ At the same time, more and more research will combine diagnostic and therapeutic partners to gradually develop diagnostic therapies and evaluate treatment effects in a various ways. ${ }^{26}$ One study ${ }^{27}$ used multimodal imaging to examine the permeability of blood vessel walls and the accumulation of fluorescently labeled liposomal NPs in atherosclerotic plaques. It was found that there is a strong correlation between the permeability established by in vivo dynamic contrast-enhanced MRI and NP plaque accumulation throughout the vessel wall. This suggests that we may be able to understand the degree of damage and inflammation of the blood vessel wall through the accumulation of NPs. Therefore, the cardiovascular imaging methods based on nanotechnology provide the feasibility for early diagnosis and differentiation of fragile plaque, and provide the basis for early prevention and treatment of atherosclerotic plaque.

Atherosclerosis is a chronic progress, and current therapies targeted for every phase mainly include two treatment options: 1) no-invasive medical therapy focusing on reduc- ing the burden of atherosclerotic plaque and stabilizing vulnerable plaques and 2) invasive revascularization therapy including percutaneous coronary interventions or coronary artery bypass graft surgery. ${ }^{28-30}$ Nanotechnology can be used for the treatment of atherosclerosis by increasing the circulation time of the whole body, reducing the systemic cytotoxicity of drugs, enhancing the solubility of the drug, lowering the required dose, combining the diagnosis and treatment of drugs to form theranostics, and increasing the cumulativeness of the drug at the specific site. ${ }^{31}$

High-dose statins whose effects of the reduction in morbidity and mortality in CAD have been observed are limited owing to off-target side effect. ${ }^{32}$ However, Broz et al depicted that pravastatin-loaded nanometer-sized vesicles functionalized by oligonucleotides to target macrophages can allow high-dose therapy for decreasing toxicity in other tissues and improving efficacy. ${ }^{33}$ Equally, fumagillin, an effective antiangiogenic drug, has been illustrated as having the potential of delivery via paramagnetic NPs targeted by integrin to reduce systemic side effects. ${ }^{34}$ Inflammatory monocytes/ macrophages play a vital role in progress of atherogenesis and rupture of the atherosclerotic plaque. Nakashiro et al ${ }^{35}$ utilized a bioabsorbable NP to delivery pioglitazone (peroxisome proliferator-activated receptor- $\gamma$ agonist, inhibiting inflammatory reaction) into circulating monocytes, which can regulate inflammatory reaction and prevent atherosclerotic plaque reptures..$^{35}$ The immune system plays an indelible role in the development of atherosclerosis, and the characteristics of immune cells are different. Some studies have combined the different physical and chemical properties of NPs and different immune cells to form a NP library. The endogenous high-density lipoprotein-based NP library can preferentially deliver therapeutic drugs to macrophages in atherosclerotic plaques, achieve targeted delivery of drugs, and also open a new path for targeted delivery of NP drugs. ${ }^{36}$ In addition, hirulog, a natural thrombin inhibitor derived from hirudin, has been conjugated onto micellar NPs to inhibit further fibrin clots from forming after coronary artery occlusion caused by thrombosis due to plaque degeneration and rupture. ${ }^{37} \mathrm{Of}$ course, the proresolving activity and efficacy of NP drugs during treatment are also well thought out. Kamaly et $\mathrm{al}^{38}$ have shown that sub-100-nm NPs are proresolving in the body, and NPs containing anti-inflammatory peptide Ac2-26 show more obvious advantages in neutrophil recruitment and enhanced resolution, and targeted NPs delivery can improve the structure of the target site. Therefore, proresolving nanomedicine therapy has a promising future in the application of chronic inflammatory diseases such as atherosclerosis. 
Restenosis after coronary artery angioplasty is affected by mechanical injury, inflammation responses and deferred endothelial healing during angioplasty. Therefore, inhibition of vascular thrombosis and restenosis is the primary factor determining long-term success of stent placement. ${ }^{39}$ To solve these problems, drug-eluting stents (DES) were invented, especially DES coated with NPs that can help locate previously ineffective drugs in interesting epitopes and produce the desired results. Nakano et al elicited a delivery platform with NP-eluting stent to target prevention of restenosis and improvement of endothelial recovery. ${ }^{40}$ Tsukie et al verified that pitavastatin-NP-eluting stent on reducing in-stent restenosis has the same efficiency as sirolimus-eluting stent, but the effect of delayed endothelial healing was not observed. On the contrary, it was observed at the sirolimus-eluting stent site. ${ }^{41}$
These nanotechnology platforms have potential for more efficient and safer equipment in the future targeting CAD. Table 1 summarizes some of the significant advances in NPs used in CAD.

\section{Application of NPs in hypertension}

Hypertension, a disease whose incidence increases with the improvement of quality of life, is not only a disease in itself but also a risk factor for many other CVDs. Increased arterial blood pressure increases the heart's load, and it also causes certain damage to other organs such as brain, eyes, kidney, and so on. Over time, a series of hypertensionrelated diseases, such as heart enlargement, ischemic cardiomyopathy, myocardial infarction, heart failure, stroke, renal dysfunction and retinopathy will appear subsequently.

Table I Some advances in nanoparticles used in CAD

\begin{tabular}{|c|c|c|c|c|}
\hline Drug/nanoparticle & Target region & Objection & Prime target & Year/reference \\
\hline $\begin{array}{l}\text { Ligand-decorated liposome } \\
\text { nanoparticles }\end{array}$ & Activated platelet & $\begin{array}{l}\text { Human and } \\
\text { rat }\end{array}$ & $\begin{array}{l}\text { Platelet-targeted delivery of drugs and imaging } \\
\text { probes }\end{array}$ & $2010^{124}$ \\
\hline $\begin{array}{l}\text { Liposomes containing } \\
\text { alendronate }\end{array}$ & Coronary artery & - & $\begin{array}{l}\text { Reduce circulating monocytes and inhibit } \\
\text { experimental restenosis }\end{array}$ & $2012^{125}$ \\
\hline $\begin{array}{l}\text { Liposome nanocarriers to } \\
\text { delivery } \mathrm{BH} 4\end{array}$ & $\begin{array}{l}\text { Prevention of early } \\
\text { atherosclerotic } \\
\text { lesion formation }\end{array}$ & Mouse & Prevention of early atherosclerotic lesion formation & $2015^{126}$ \\
\hline $\begin{array}{l}\text { Gd-containing } \\
\text { immunomicelles }\end{array}$ & $\begin{array}{l}\text { Macrophages in } \\
\text { atherosclerosis }\end{array}$ & Murine & Detection of macrophage-rich plaques & $2006^{127}$ \\
\hline $\begin{array}{l}\text { Lipid-polymeric nanoparticles } \\
\text { loaded with paclitaxel }\end{array}$ & Coronary artery & Rat & Treatment of injured vasculature due to $\mathrm{PCl}$ & $2011^{128}$ \\
\hline $\begin{array}{l}\text { PLGA nanoparticles } \\
\text { containing alendronate }\end{array}$ & Coronary artery & Rabbit & $\begin{array}{l}\text { Depletion of circulating monocytes, inhibition of } \\
\text { macrophages proliferation and restenosis }\end{array}$ & $2009^{129}$ \\
\hline Mn G8 dendrimers & $\begin{array}{l}\text { Oxidation-specific } \\
\text { epitopes }\end{array}$ & Mouse & Detection of atherosclerotic plaques & $2015^{130}$ \\
\hline $\begin{array}{l}\text { Tadpole dendrimer loaded } \\
\text { with siRNA }\end{array}$ & ATIR & Rat & Improvement of cardiac function recovery & $20 \mid 3^{|3|}$ \\
\hline $\begin{array}{l}\text { Rapamycin-loaded gel-like } \\
\text { nanoparticles }\end{array}$ & Carotid artery & Rat & $\begin{array}{l}\text { Prevention of neointimal hyperplasia and } \\
\text { reendothelialization of vascular injury }\end{array}$ & $2008^{132}$ \\
\hline MNP-loaded primary ECs & Gene expression & $\begin{array}{l}\text { Lewis inbred } \\
\text { rats }\end{array}$ & $\begin{array}{l}\text { Reendothelialization by the implant and alleviating } \\
\text { neointimal hyperplasia }\end{array}$ & $2015^{133}$ \\
\hline Paclitaxel-loaded MNPs & Carotid stent & Rat & Inhibition of in-stent restenosis & $2010^{134}$ \\
\hline HDL covered by liposomes & $\begin{array}{l}\text { Aortic cholesterol } \\
\text { contents }\end{array}$ & $\begin{array}{l}\text { Cholesterol- } \\
\text { fed rabbits }\end{array}$ & $\begin{array}{l}\text { Reduction of aortic plaque volume and cholesterol } \\
\text { content }\end{array}$ & $2010^{135}$ \\
\hline $\begin{array}{l}\text { Colloidal nanoparticles- } \\
\text { loaded thrombin }\end{array}$ & Acute arterial & Mouse & Localized treatment of acute thrombosis & $2011^{136}$ \\
\hline $\begin{array}{l}\text { Superparamagnetic } \\
\text { nanoparticles derived } \\
\text { from fluorophores }\end{array}$ & Areas of atheroma & Rabbit & Identification of biologically high-risk atheroma & $2017^{137}$ \\
\hline $\begin{array}{l}\text { PDLLA nanoparticles } \\
\text { containing sirolimus }\end{array}$ & Smooth muscle cells & - & $\begin{array}{l}\text { Inhibiting the proliferation of smooth muscle cells } \\
\text { and speeding up the proliferation of endothelial cells }\end{array}$ & $2018^{138}$ \\
\hline
\end{tabular}

Abbreviations: ATIR, angiotensin II (Ang II) type I receptor; BH4, tetrahydrobiopterin; CAD, coronary artery disease; ECs, endothelial cells; Gd, gadolinium; HDL, high-density lipoprotein; MNP, magnetic nanoparticle; Mn, manganese; PCl, percutaneous coronary interventions; PDLLA, polymer poly (DL-lactide); PLGA, poly-(lactic-coglycolic) acid; siRNA, small-interfering RNA. 
According to WHO, 1 billion people were suffering from hypertension in 2008 , and the mortality rates of ischemic heart disease and stroke resulted by hypertension were $45 \%$ and $51 \%$, respectively. ${ }^{42}$

At present, the main clinical antihypertensive drugs can be divided into the following categories: angiotensinconverting enzyme inhibitors, calcium channel blockers (CCBs), angiotensin II receptor blockers, central sympathomimetic drugs, diuretics, alpha blockers, beta blockers and vasodilator. ${ }^{43}$ However, the majority of these antihypertension drugs show some defects, such as poor water solubility, low bioavailability, short half-life and so on. ${ }^{42}$ At the same time, because of the high dosing frequency and long-term use, some undesirable side effects are coming up, such as dry cough caused by captopril, male breast hyperplasia caused by spironolactone, etc. In order to use these drugs effectively and safely, it is necessary to provide a drug delivery system with low doses, increased bioavailability, increased selectivity and reduced adverse effects. As mentioned above, some NPs-based oral drug management systems provide alternative strategies for overcoming these difficulties. ${ }^{44}$

So far, the NPs used in the treatment of hypertension mainly include nanoemulsion, liposome, polymeric NPs, solid lipid NPs (SLNs) and nanostructured lipid carriers. One example is the formulation of olmesartan medoxomil $(\mathrm{OM})$ in the nanoemulsion system designed to reduce its adverse solubility and bioavailability. Olmesartan, playing a role in lowering blood pressure by selectively blocking of angiotensin II-AT1 receptor, shows poorly oral bioabsorptivity and availability astricted by poor water solubility and permeability.

The pharmacokinetic study of OM nanoemulsion that was carried out to detect changes in plasma concentration of active olmesartan in rats after oral administration indicated 2.8 times increase compared with the conventional dose; furthermore, the effect of antihypertension demonstrated better and longer with three times reduction in the routine dose. This finding indicates that $\mathrm{OM}$ nanoemulsion can significantly improve its bioactivity by increasing its solubility, thereby enhancing its bioavailability and promoting the improvement of clinical application. ${ }^{45}$ Other nanoemulsion containing a variety of drugs, such as ramipril, amlodipine, valsartan, lacidipine, carvedilol and so on, have been shown to increase the bioavailability and antihypertensive efficacy of these drugs to varying degrees. ${ }^{46-50}$

In addition to nanoemulsion, many additional formulations can be designed using nanotechnology to improve the efficacy and safety of antihypertensive drugs. Lipotomes containing lacidipine, a hydrophobe $\mathrm{CCB}$, also have been considered as a promising strategy to improve the bioavailability of insoluble drugs ${ }^{51}$ Shah et al,${ }^{52}$ indicated that felodipine-loaded poly-(lactic-co-glycolic) acid (PLGA) NPs can control blood pressure and change ECG for extended duration by bypassing the prophase metabolism and providing sustained drug release. ${ }^{52}$ Moreover, Niaz et al ${ }^{53}$ elaborated the new polymer nanowire is a new type of antihypertensive drug (angiotensin-converting enzyme inhibitor, beta blockers, and $\mathrm{CCB}$ ) with stable, high cation and even dispersion. It has good encapsulation efficiency. The hydrophilicity of chitosan as a biological carrier helps to improve the oral bioavailability of antihypertension drugs. ${ }^{53}$ Dudhipala et a ${ }^{54}$ devised a nisoldipine SLN whose peak serum concentration $\left(C_{\max }\right)$ and $\mathrm{AUC}_{\text {total }}$ are significantly higher than oral drug suspension $(12.55 \pm 0.6 \mathrm{mg} / \mathrm{mL}$ vs $7.53 \pm 0.13 \mathrm{mg} / \mathrm{mL}$, $96.15 \pm 3.92 \mathrm{mg} / \mathrm{mL} / \mathrm{h}$ vs $44.13 \pm 2.90 \mathrm{mg} / \mathrm{mL} / \mathrm{h}$, respectively). Additionally, the removal rate of nisoldipine in SLN formulation is relatively slow, which makes biological half-life $\left(t_{1 / 2}\right)$ and mean residence time of SLN formulation higher. The oral bioavailability of SLN preparation was 2.17 times higher than that of suspension..$^{54}$ However, SLN has some limitations, such as the formation of solid lipid into crystal as time goes on, thereby reducing the encapsulation efficiency and the amount of drug loading with time, which led to the development of nanostructured lipid carrier composed of liquid lipids. Ranpise et $\mathrm{al}^{55}$ developed a nanostructured lipid carrier containing lercanidipine hydrochloride, a poorly water-soluble drug, with a relative bioavailability of only $10 \%$. In vitro release studies have shown that the release rate of the drug in the acid buffer $\mathrm{pH} 1.2$ is $19.36 \%$, indicating that the drug in the nanostructured lipid carrier is still encapsulated under the acidic $\mathrm{pH}$ condition. In vitro studies showed that the release rate of drugs increased from $10 \%$ to $60.54 \%$ in 24 hours. In vivo, pharmacodynamic studies showed that nanostructured lipid carriers could release lercanidipine hydrochloride in a controlled manner for a longer time compared with ordinary drugs. ${ }^{55}$

Furthermore, the limitations of the current nitric oxide (NO) delivery systems and rapid degradation of siRNA upon administration for gene therapy stimulate an enormous interest in the development of compounds that produce such vasoactive substances in a controlled and sustained manner to treat CVDs such as hypertension. Cabrales et a ${ }^{56}$ prepared NO-releasing NPs using a new platform based on hydrogel/ glass hybrid NPs. This nanomaterial maintains a stable form of NO or NO precursor (nitrite) during drying, while exposed to moisture, these NPs slowly release the treatment level 
of NO. After the administration of this NO NP, circulating NO level can reduce the average arterial blood pressure and increase the NO exhaled concentration in a few hours. ${ }^{56} \mathrm{NPs}$ can be proposed as a delivery system to prevent the degradation of siRNA by endonuclease and exonuclease in blood, serum and cells. Liposome is a cationic liposome made of DOTAP (N-[1-(2,3-dioleoyloxy)]-N-N-N trimethyl ammonium propane). The expression of $\beta 1$-adrenergic receptor can be reduced by intravenous administration, and the blood pressure is controlled for 12 days. ${ }^{42}$

\section{NPs and pulmonary hypertension}

Pulmonary arterial hypertension (PAH) is a highly threatening and progressive disease characterized by increased pulmonary vascular resistance and increased pulmonary artery pressure. Continuous increase of pulmonary vascular resistance leads to pulmonary vasoconstriction and structural remodeling, which further affects the right heart function and ultimately leads to right heart failure and death. ${ }^{57}$ The common targeted drugs for PAH include prostacyclin (prostaglandin I2), endothelin receptor antagonists, phosphodiesterase type-5 inhibitors and a soluble guanylate cyclase stimulator. These vasodilators have shown certain effectiveness in the past applications. ${ }^{58}$ However, due to the poor bioavailability and side effects of the drugs, their overall therapeutic ability is limited. In order to solve these problems, the drug delivery system mediated by NPs can be used as a novel alternative strategy.

Bosentan, a selective and competitive antagonist of endothelin receptor, has been designed to nanosuspensions for enhancing solubility and absorption by an increase of its contact surface. The study showed that the solubility of bosentan NPs increases seven times higher than coarse bosentan. ${ }^{57}$ Akagi et al $^{59}$ described a PLGA NP incorporated with beraprost (a prostacyclin analog) that significantly reduced pulmonary vascular resistance and inhibited pulmonary vascular remodeling in rat models. Beraprost-NPs also improved the survival rate of rat model and decreased the occurrence of side effects. ${ }^{59}$ Also, in another study, authors reported that imatinib-incorporated NPs exhibited more significant inhibition of pulmonary arterial smooth muscle cells proliferation than imatinib (a tyrosine kinase inhibitor) after intratracheal administration. ${ }^{60}$ Other studies have shown consistent results, including various NPs that incorporate with pitavastatin, fasudil and oligonucleotides, which have shown better effects on inhibiting pulmonary vascular remodeling, inducing the decline of PAH, and improving survival rates. ${ }^{61-63}$ Therefore, this platform based on nanotechnology can serve as a novel alternative tool for improving the effectiveness and alleviating side effects of treatment of PAH.

\section{Application of NPs for treating atrial fibrillation (AF)}

$\mathrm{AF}$ is the most common clinical arrhythmia, accounting for approximately one-third of all arrhythmia-related inpatients. AF significantly affects morbidity and mortality in patients as the result of the high risk of stroke. ${ }^{64}$ Catheter ablation has become a major treatment for drug refractory AF. However, the success and maintenance of cardioversion has been limited by a lack of sufficient understanding of the mechanisms for the occurrence and maintenance of AF. Yu et a ${ }^{65}$ proposed a novel ablation strategy utilizing functionalized magnetic NPs (MNPs). Previous animal experiments have demonstrated that ganglionated plexi (GP) plays an important role in the occurrence and maintenance of AF, and clinical evidence also suggested that the main GP ablation can increase the success of standard pulmonary vein isolation by catheter ablation for treating AF. ${ }^{66}$ Selective ablation of GP requires their accurate location. At present, the location of target GP is achieved by detecting the sites where high-frequency stimulation slows down heart rate and then ablation at that site, that is, endocardial catheter technique. Better methods to identify and ablate these focal neural networks can be used as an auxiliary therapy for conventional cryoablation or radiofrequency ablation.

Inspiringly, Yu et al ${ }^{65}$ described a technique using superparamagnetic $\mathrm{Fe}_{3} \mathrm{O}_{4}$ NPs that were coated with thermoresponsive polymeric hydrogel (shell) when contacting body temperature in vivo to release neurotoxic agent contained therein. The results showed that in six dogs in which MNPs were injected directly into the anterior right GP, the sinoatrial node slowing response induced by high frequency stimulation was significantly inhibited $(40 \% \pm 8 \%$ at baseline; $21 \% \pm 9 \%$ at 2 hours), and the lowest voltage of high frequency stimulation inducing AF was increased significantly $(5.9 \pm 0.8 \mathrm{~V}$ at baseline; $10.2 \pm 0.9 \mathrm{~V}$ at 2 hours). In the other four dogs, MNPs were injected into the circumflex artery supplying the inferior right GP (IRGP) and were attracted to IRGP by magnets sutured on the epicardial surface, which inhibited the function of IRGP and decreased the ventricular rate. These results demonstrate that targeted delivery of drugs based on nanotechnology may have a promising future in the treatment of AF.

\section{NPs application in the treatment of AMI}

After myocardial infarction, the cardiac function is continuously impaired due to the low proliferation and limited selfrepair ability of myocardial cells. Conventional myocardial blood supply restoration cannot repair the apoptotic CMs. Therefore, stem cell therapy has emerged as a new treatment 
method. ${ }^{67}$ However, despite the great development of this therapy, the delivery of targeted stem cells and the tracking or detection of their proliferation still need efforts to optimize. In order to overcome these shortcomings, new methods are needed to achieve high concentration cells in damaged tissues and to monitor their proliferation and survival. MRI has become a reliable and safe technology for tracking these cells. However, it is important that the sensitivity and success of this technology largely depend on the contrast medium used. Iron oxide superparamagnetic NPs, due to their unique magnetic properties and favorable biocompatibility, can be used to direct and monitor the therapeutic effects of stem cells on AMI. It has been recognized as one of the most promising contrast agents for stem cell markers. ${ }^{68,69}$

Additionally, Binsalamah et $\mathrm{al}^{70}$ applied a chitosanalginate NP containing placental growth factor (PlGF), a key molecule in angiogenesis and vasculogenesis, to improve cardiac function at the site of AMI. The results demonstrated that using NPs as a carrier instead of direct injection of PlGF in the treatment of AMI can provide a sustained release of PlGF and enhance the positive effects of growth factors on acute myocardial ischemia. ${ }^{70}$

Moreover, Nakano et $\mathrm{al}^{40}$ have proposed a PLGA NP incorporated with irbesartan (anangiotensin II receptor blockers) to inhibit the recruitment of inflammatory monocytes which contribute to myocardial ischemia-reperfusion injury, further decreasing the infarct size and meliorating left ventricular remodeling. ${ }^{71}$ In a similar manner, Galagudza et $\mathrm{al}^{72}$ designed a silica NPs loaded with adenosine (a prototype cardioprotective agent) to reduce infarct size while reducing hypotension and slow heart rate from systemic adenosine use. ${ }^{72}$ Of special interest, another study found that phosphatidylserine-presenting liposomes could act as an anti-inflammatory effect by mimicking apoptosis cells being swallowed by macrophages and following that the macrophages secreted high levels of anti-inflammatory cytokines and regulated the expression of certain receptors markers. ${ }^{73}$

\section{Roles of NPs in other CVDs}

As a new drug delivery platform, NPs also perform well in many other CVDs. Fullerene NPs significantly protect brain cells from ischemia or reperfusion injury caused by cerebral infarction by scavenging free radicals from oxidative stress. At the same time, certain NPs can be combined with some neuroprotective drugs to greatly promote permeability and make it more smoothly cross the blood-brain barrier to play a vital role in the treatment of ischemic stroke. ${ }^{74-76}$ Of course, NPs can also target thrombolytic drugs, such as tissue plasminogen activator after thromboembolism, to play the role of rapid recanalization of occluded blood vessels and alleviate the inefficiency and many side effects of systemic medication, including the high risk of bleeding complications. ${ }^{77} \mathrm{NPs}$ as a drug-releasing platform for periadventitial drug delivery have stirred up the recent research in nanomedicine to restrain intimal hyperplasia (IH) after open vascular reconstructions in treatment of atherosclerosis, such as application in IH antiproliferation of saphenous vein grafts. ${ }^{78}$

In short, NPs have shown excellent properties in the transportation of many drugs and have a promising prospect of application.

\section{Nanomaterials for CVDs}

After myocardial infarction, cardiac myocyte apoptosis, myofibroblast and macrophage migration to the infarct site to repair the heart tissue resulting in scar tissue, affect the systolic function of the heart and eventually cause heart failure. ${ }^{79}$ Heart transplantation is the most effective treatment for patients with heart failure when they reach the final stage of heart failure. However, due to the lack of heart donors and immune rejection, very few people are lucky to receive transplantation treatment. ${ }^{80}$ In order to overcome these bottlenecks, cell-based therapy and tissue engineering have gradually become a hot research direction. ${ }^{81,82}$ Tissue engineering is an interdisciplinary field that aims to create biomimetic materials that generate scaffolds that usually seed with cells to produce or repair functional organs. Nanomaterials are usually made from metals, ceramics, polymers, organic materials or composites, because they are synthesized on a nanoscale scale, with a significant increase in surface area-volume ratio and roughness, thus enhancing mechanical, electrical, optical, catalytic and magnetic properties. It is clear that the superior material properties of nanomaterials have shown the most promising results in cardiac myocyte tissue engineering. ${ }^{83}$

Nanomaterials are usually classified, according to their origin, as natural or synthetic biomaterials. It is known that natural biomaterials mainly found in the ECM, including collagen, fibrin and hyaluronan, have nanoscale dimensions. ${ }^{79}$ The nanofiber scaffolds incorporated with these materials by electrospinning have been used for cardiac tissue engineering applications, showing higher percentage of cellular attachment and the availability of multiple focal sticky points. ${ }^{79}$ Nevertheless, in some cases, the shortcomings of these materials should be carefully considered. Proteases in organisms degrade natural substances too quickly, limiting the use of these materials as long-term implants. ${ }^{84}$ In particular, these materials may 
contribute to fibrosis, foreign body reactions together with oxidative stress and immune response when used in vivo.

The application of synthetic materials in many occasions provides a better control of the eventual effects due to their facile fabrication and widely modified mechanical properties. Structure, pore size and orientation, mechanical strength, degradation methods and so on can be optimized according to the actual demand. Poly (ethylene glycol) (PEG), a US Food and Drug Administration-approved polymer, is regularly used for scaffolds that can offer cellular structural support and guide tissue regeneration. Kim et $\mathrm{a}^{85}$ introduced a CM substrate that was made of PEG with nanopillar topography and they found that cell adhesion was apparently increased on PEG nanopillars as compared to conventional PEG substrate and that nanopatterned substrate stimulated cell-cell binding in colonizing CMs. Later, another study ${ }^{86}$ that used PEG hydrogels to determine whether CMs could be guided by nanomorphology embedded on the substrate showed that compared with the random orientation on the pattern-free nanotopography substrate, the uniform $\mathrm{CM}$ orientation is allowed on the PEG substrate with patterned nanomorphology. It is also important to observe the larger cell diameters on the patterned substrate, which indicates that the nanomorphology affects the cell size.

Polyglycolic acid (PGA) and polycaprolactone (PCL) are also promising candidates for scaffolding since they have some advantages such as desirable degradation rates all while being nontoxic, biocompatible, hydrophilic and low cost, but also has soft and flexible characteristics. Aghdam et al ${ }^{87}$ fabricated PCL:PGA nanofibrous scaffold by electrospinning for studying cell attachment and proliferation of cardiac progenitor cells. They found that after 6 days of culture on the scaffold of PCL:PGA with weight ratio of $65: 35$, the cell viability was the highest and attributed to the enhancement of hydrophilicity. Equally important, PLGA has been diffusely used for tissue engineering applications for combining the advantages of poly-lactic acid and PGA. Simon-Yarza et $\mathrm{al}^{88}$ used PLGA to prepare nanofiber scaffolds containing Neuregulin-1 (Nrg), a cardioactive growth factor. The results showed Nrg-containing fibers have effective adhesion, integration and biocompatibility with damaged heart tissue and that an increase of M2:M1 macrophage ratio after implantation suggests that tissue remodeling is induced. Scaffolds made of other nanomaterials, such as polypyrrole, ${ }^{89}$ carbon nanotubes ${ }^{90-92}$ and electrospun poly(glycerol sebecate), ${ }^{93}$ have shown excellent performance in tissue engineering of CMs.

Another approach for treating injured heart tissue after a heart attack is to use engineered cardiac tissue patch, which is usually produced by implanting heart cells into a threedimensional scaffold of porous biomaterials. ${ }^{94}$ One study ${ }^{95}$ described that compared with the traditional polymer matrix, the carbon nanofibers embedded in PLGA make the growth of CMs more robust and that 50:50 PLGA to carbon nanofibers composite ratios at PLGA density of $0.025 \mathrm{~g} / \mathrm{mL}$ enhanced $\mathrm{CM}$ function by mimicking heart tissue tensile strength and conductivity and enhancing the adsorption of proteins known to promote $\mathrm{CMs}$ function. Moreover, Malki et $\mathrm{al}^{96}$ developed a engineered cardiac patch composed of albumin electrospun fibers and gold nanorods with cardiac cell seeded in. When localized on the myocardium and irradiated with near infrared laser $(808 \mathrm{~nm})$, this patch can absorb light and convert it into heat power, which changes the molecular structure of the fibrous scaffold locally, and makes it attached to the wall of the heart strongly but safely.

Of course, injectable scaffolds are favored by researchers for their simple and minimally invasive procedures because they can be injected through syringes or catheters. One study conducted by Lin et $\mathrm{al}^{17}$ demonstrated that when injecting self-assembling peptide nanofibers into myocardium, they can enhance the thickness of infarcted myocardium and inhibit ventricular remodeling, whereas the implantation of nanofibers containing autologous bone marrow mononuclear cell improves cell retention and cardiac functions after MI in pigs. ${ }^{97}$ Another common method is to prepare injectable gel from acellular ECM. For example, Singelyn et $\mathrm{al}^{98}$ extracted and decellularized porcine cardiac tissue to form myocardial matrix with the ability to self-assemble to form a nanofibrous structure in vivo. It can also be used to delivery stem cells ${ }^{99}$ or cell factors ${ }^{100}$ to repair infarcted myocardium and improve cardiac function. Injectable materials are likely to be exemplary techniques for cardiac tissue engineering because of their ease of use, but there are still many obstacles to overcome, such as the correct guidance of the infarct area and the control of the arrival of the final stent geometry. Transporting materials through ducts can avoid invasive surgery, reduce patient recovery time and infection opportunities. Infarcted areas after myocardial infarction are unstable, and intramyocardial injection may increase the risk of ventricular rupture, leading to safety problems in patients with AMI. ${ }^{101}$

Of course, nanomaterials are not only used in myocardial tissue engineering but also have outstanding applications in other cardiovascular fields. In one study, authors demonstrated that a nanopolyplex as a delivery platform of a mitogen-activated protein kinase-activated protein kinase 2 inhibitory peptide into vascular graft intima can significantly increase long-term patency by inhibition of inflammatory 
Table 2 A brief summary of the application of nanotechnology to cardiovascular disease

\begin{tabular}{|c|c|c|}
\hline Coronary artery disease & Hypertension & Pulmonary hypertension \\
\hline $\begin{array}{l}\text { - Nanoparticles for diagnosis: iron oxide } \\
\text { fluorescent, I9F perfluorocarbons, gold, } \\
\text { gadolinium-coated perfluorocarbon } \\
\text { - Nanoparticles for therapy: pravastatin, } \\
\text { fumagillin, pioglitazone, anti-inflammatory } \\
\text { peptide }\end{array}$ & $\begin{array}{l}\text { - Nanoemulsion: olmesartan medoxomil, ramipril, } \\
\text { amlodipine, valsartan, lacidipine, carvedilol } \\
\text { - Lipotomes: lacidipine, siRNA } \\
\text { - Nanowire: ACEI, BBS, CCB } \\
\text { - Nanostructured lipid carrier: lercanidipine } \\
\text { - Hydrogel/glass hybrid: nitric oxide } \\
\text { - Nanoparticles: felodipine }\end{array}$ & $\begin{array}{l}\text { - Nanosuspensions: bosentan } \\
\text { - Nanoparticles: beraprost, imatinib, } \\
\text { pitavastatin, fasudil, oligonucleotides }\end{array}$ \\
\hline Atrial fibrillation & Acute myocardial infarction & Ischemic stroke \\
\hline $\begin{array}{l}\text { - Superparamagnetic } \mathrm{Fe}_{3} \mathrm{O}_{4} \text { nanoparticles } \\
\text { loaded with neurotoxic agent } \\
\text { - Nanomaterials: Parylene- } \mathrm{C} \text { with } \\
\text { dexamethasone and amiodarone }\end{array}$ & $\begin{array}{l}\text { - Diagnosis: iron oxide superparamagnetic nanoparticles } \\
\text { - Nanoparticles: PIGF, irbesartan, adenosine, } \\
\text { phosphatidylserine } \\
\text { - Nanomaterials: PEG, PGA, PCL, PLA, PLGA, PPy, } \\
\text { peptides nanofibers }\end{array}$ & - Nanoparticles: tPA, hirulog \\
\hline
\end{tabular}

Abbreviations: ACEI, angiotensin-converting enzyme inhibitors; BBS, beta blockers; CCBs, calcium channel blockers; PCL, polycaprolactone; PEG, poly (ethylene glycol); PGA, polyglycolic acid; PLA, poly-lactic acid; PLGA, poly-(lactic-co-glycolic) acid; PPy, polypyrrole; PIGF, placental growth factor; tPA, tissue plasminogen activator.

response and cellular proliferation. ${ }^{102}$ Collagen, a natural nanostructural biodegradable material, seems to be more suitable for the manufacture of the external scaffold, because it not only plays a protective role for venous bridges in arterial environments but also helps to reduce IH with features of low immunogenicity and excellent biocompatibility, porous structure and desired permeability. ${ }^{103} \mathrm{Li}$ et al ${ }^{104}$ studied the effects of external scaffolds made of collagen on venous graft hemodynamics and $\mathrm{IH}$ and the results demonstrated that the rabbit arteriovenous graft coated with collagen external scaffold showed higher blood velocity and blood flow, thinner intima and media, and smaller diameter. Moreover, the external scaffolds made of other collagen or polymer have been widely used in the study of inhibiting the neointimal proliferation and maintaining the fluidity of vein grafts, and have shown remarkable effect and gratifying application prospect. ${ }^{105}$ What's more interesting is that nanomaterials can also be used to treat and prevent AF. A nanostructured film fabricated with Parylene-C was loaded with dexamethasone and amiodarone, and then was localized to epicardium of rabbit model to inhibit perioperative inflammation and AF. ${ }^{106}$ The results demonstrated that the nanostructured Parylene-C films possess the capacity to release lastingly drug delivery, and most notably to reduce inflammatory reaction, epicardial neotissue fibrosis and occurrence of AF. A brief summary of the application of nanotechnology to CVDs is shown in Table 2.

\section{Application of nanotechnology in cardiac and cardiothoracic surgery robots}

The combination of endoscopy and advanced control technology makes robotic-assisted surgery possible. ${ }^{107,108}$
Robotics is not based on nanoscale robots that flow through the body, but on sensors, imaging, navigation, brakes, etc., which are based on nanotechnology to enhance the ability of surgeons. The surgical robot technology, especially the robot which can be controlled by magnet at the end of the catheter, has a great influence on cardiothoracic operation and intubation in cardiovascular surgery. ${ }^{109,110}$ The remote image-guided magnetic catheter guidance system has been used in ablation operation for the treatment of $\mathrm{AF}^{111,112}$ and tachycardia. ${ }^{113-115}$ Robotic-assisted catheter technology has also been widely used in mitral valve repair, ${ }^{116,117}$ and robotics have been used in minimally invasive surgery to treat coronary artery stenosis ${ }^{118,119}$ or to assist in navigation in thickened hypertrophic obstructive cardiomyopathy with septum myectomy, ${ }^{120}$ which is associated with sudden cardiac death syndrome.

The tracking and compensation of beating heart activity using robot technology can be regarded as a great challenge to robotics. In recent years, it has met this requirement to a large extent, but even so, there is still room for development. This is due to the application of increasingly sophisticated mathematical methods and adaptive control strategies for robot tracking and movement. ${ }^{121}$ The realization of these real-time advanced computing methods depends on the advance of fast computing, electronic control, sensors and actuators based on nanotechnology. As these abilities continue to develop, new theories of control will emerge that will be applied to tracking the movements of the heart, eyes and other parts of the body for the purpose of surgery, treatment and diagnosis. ${ }^{122}$

\section{Conclusion and prospects}

Nanotechnology as a new type of science provides a bright prospect and hope for clinicians to achieve the goals that until recently seemed impossible to achieve, but it is still necessary 
to further deepen knowledge and increase the application of nanotechnology. Nanomedicine has great potential in the treatment of CAD. Effective nanodrug delivery systems for different drugs are being developed. However, the problems facing their implementation are many, for instance, nondeterminacy of the age of a nanomaterial in a biological cell, no sufficient information about the biological safety of NPs at the cellular level, and direct toxicity inside the living cell based on the chemical makeup. At the same time, nanomaterials may also produce allergic reactions, inflammation and increased angiogenic intima in the body. In addition, DES may cause deformities and injuries, and some clinical disasters have occurred. Therefore, more and more studies consider combining nanotechnology and gene therapy methods (eg, pDNA and RNAi) to modify gene expression and generate signaling molecules to inhibit the growth of diseased cells and hyperplasia, and cause apoptosis. Thereby fundamentally solving the disease progression. ${ }^{17}$ In addition, although nanotechnology has achieved pleasing results in CVDs, it is still mostly in the experimental stage, and for patients with severe myocardial damage, it cannot completely repair the damaged myocardium, so many patients who cannot receive heart transplant eventually die from heart failure. Therefore, more and more scientists try to combine the superiority of nanotechnology with stem cells or gene therapy, so-called tissue engineering or genetic engineering, to provide a bright future for the diagnosis and treatment of CVDs. ${ }^{26,123}$ Therefore, the clinical application of nanotechnology should be carefully evaluated through randomized trials. Collaborative research between biomedical engineers and clinicians is essential for the development of practical and effective treatment of nanoscale models.

Overall, there is still a long road ahead for research and clinical translations in application of nanotechnology. Great progress in nanomedicine has greatly improved the current treatment of CVDs. With the shrinking of treatment and the expansion of scientific curiosity, the future of CVDs treatment is indeed very exciting.

\section{Acknowledgments}

The authors acknowledge to Professor Zhiyong Qian (Professor of State Key Laboratory of Biotherapy, Sichuan University, the main research directions are nanobiotechnology, biomedical polymer materials, pharmacy, etc.) for improving our manuscript. This work was supported by grants from the National Key Project Program during the 13th 5-Year Plan Period of China (2016YFC1302003) and from the Major Science and Technology Project of Sichuan
Province, China (No 2017SZ0056), and the Scientific Research Project of Sichuan Health and Family Planning Commission, China (No 17PJ177).

\section{Author contributions}

All authors contributed to data analysis, drafting or revising the article, gave final approval of the version to be published, and agree to be accountable for all aspects of the work.

\section{Disclosure}

The authors report no conflicts of interest in this work.

\section{References}

1. Emerich DF, Thanos CG. Nanotechnology and medicine. Expert Opin Biol Ther. 2003;3(4):655-663.

2. Feynman RP. There's plenty of room at the bottom [data storage]. J Microelectromech Syst. 2002;1(1):60-66.

3. Zhao Y, Yakobson BI, Smalley RE. Dynamic topology of fullerene coalescence. Phys Rev Lett. 2002;88(18):185501.

4. Haddad M, Popovtzer R, Yariv I, Motiei M,FixlerD. סקירה ננומטית תמציתית) [Concise nanomedicine review]. Harefuah. 2018;157(4):232-236. Hebrew.

5. Tibbals HF. Medical Nanotechnology and Nanomedicine. Boca Raton (FL): CRC Press, LLC; 2010

6. Nichols M, Townsend N, Scarborough P, Rayner M. Cardiovascular disease in Europe 2014: epidemiological update. Eur Heart J. 2014; 35(42):2929-2959.

7. Nugent HM, Edelman ER. Tissue engineering therapy for cardiovascular disease. Circ Res. 2003;92(10):1068-1078.

8. Sanganalmath SK, Bolli R. Cell therapy for heart failure: a comprehensive overview of experimental and clinical studies, current challenges, and future directions. Circ Res. 2013;113(6):810-834.

9. Writing Group Members, Mozaffarian D, Benjamin EJ, et al. Heart disease and stroke statistics-2016 update: a report from the American Heart Association. Circulation. 2016;133(4):e38-e360.

10. Wong IY, Bhatia SN, Toner M. Nanotechnology: emerging tools for biology and medicine. Genes Dev. 2013;27(22):2397-2408.

11. Brito L, Amiji M. Nanoparticulate carriers for the treatment of coronary restenosis. Int J Nanomedicine. 2007;2(2):143-161.

12. Libby P, Ridker PM, Hansson GK. Progress and challenges in translating the biology of atherosclerosis. Nature. 2011;473(7347):317-325.

13. Badimon L, Vilahur G. Thrombosis formation on atherosclerotic lesions and plaque rupture. J Intern Med. 2014;276(6):618-632.

14. Cominacini L, Garbin U, Mozzini C, et al. The atherosclerotic plaque vulnerability: focus on the oxidative and endoplasmic reticulum stress in orchestrating the macrophage apoptosis in the formation of the necrotic core. Curr Med Chem. 2015;22(13):1565-1572.

15. Cagle $\mathrm{S}$, Cooperstein N. Coronary artery disease: diagnosis and management. Prim Care. 2018;45(1):45-61.

16. Mangla A, Oliveros E, Williams KA, Kalra DK. Cardiac imaging in the diagnosis of coronary artery disease. Curr Probl Cardiol. 2017;42(10): 316-366.

17. Karimi M, Zare H, Bakhshian Nik A, et al. Nanotechnology in diagnosis and treatment of coronary artery disease. Nanomedicine. 2016;11(5):513-530.

18. Aikawa E, Nahrendorf M, Figueiredo JL, et al. Osteogenesis associates with inflammation in early-stage atherosclerosis evaluated by molecular imaging in vivo. Circulation. 2007;116(24):2841-2850.

19. Flögel U, Ding $Z$, Hardung $H$, et al. In vivo monitoring of inflammation after cardiac and cerebral ischemia by fluorine magnetic resonance imaging. Circulation. 2008;118(2):140-148. 
20. Yeager D, Chen YS, Litovsky S, Emelianov S. Intravascular photoacoustics for image-guidance and temperature monitoring during plasmonic photothermal therapy of atherosclerotic plaques: a feasibility study. Theranostics. 2013;4(1):36-46.

21. Laufer E, Winkens H, Corsten M, Reutelingsperger C, Narula J, Hofstra L. PET and SPECT imaging of apoptosis in vulnerable atherosclerotic plaques with radiolabeled Annexin A5. Q J Nucl Med Mol Imaging. 2009;53(1):26-34.

22. Quillard T, Libby P. Molecular imaging of atherosclerosis for improving diagnostic and therapeutic development. Circ Res. 2012;111(2): 231-244.

23. De Saint-Hubert M, Bauwens M, Deckers N, et al. In vivo molecular imaging of apoptosis and necrosis in atherosclerotic plaques using microSPECT-CT and microPET-CT imaging. Mol Imaging Biol. 2014;16(2):246-254

24. Moreno PR, Purushothaman KR, Fuster V, et al. Plaque neovascularization is increased in ruptured atherosclerotic lesions of human aorta: implications for plaque vulnerability. Circulation. 2004;110(14) 2032-2038.

25. Jaffer FA, Libby P, Weissleder R. Molecular imaging of cardiovascular disease. Circulation. 2007;116(9):1052-1061.

26. Mahmoudi M, Yu M, Serpooshan V, et al. Multiscale technologies for treatment of ischemic cardiomyopathy. Nat Nanotechnol. 2017;12(9):845-855.

27. Lobatto ME, Calcagno C, Millon A, et al. Atherosclerotic plaque targeting mechanism of long-circulating nanoparticles established by multimodal imaging. ACS Nano. 2015;9(2):1837-1847.

28. Rhee JW, Wu JC. Advances in nanotechnology for the management of coronary artery disease. Trends Cardiovasc Med. 2013;23(2):39-45.

29. Serruys PW, Kutryk MJB, Ong ATL. Coronary-artery stents. N Engl J Med Overseas Ed. 2006;354(5):483-495.

30. Kolkailah AA, Alreshq RS, Muhammed AM, Zahran ME, Anas ElWegoud M, Nabhan AF. Transradial versus transfemoral approach for diagnostic coronary angiography and percutaneous coronary intervention in people with coronary artery disease. Cochrane Database Syst Rev. 2018;4:CD012318.

31. Lewis DR, Kamisoglu K, York AW, Moghe PV. Polymer-based therapeutics: nanoassemblies and nanoparticles for management of atherosclerosis. Wiley Interdiscip Rev Nanomed Nanobiotechnol. 2011;3(4):400-420.

32. Cannon CP, Steinberg BA, Murphy SA, Mega JL, Braunwald E. Metaanalysis of cardiovascular outcomes trials comparing intensive versus moderate statin therapy. J Am Coll Cardiol. 2006;48(3):438-445.

33. Broz P, Ben-Haim N, Grzelakowski M, Marsch S, Meier W, Hunziker P. Inhibition of macrophage phagocytotic activity by a receptor-targeted polymer vesicle-based drug delivery formulation of pravastatin. J Cardiovasc Pharmacol. 2008;51(3):246-252.

34. Winter PM, Neubauer AM, Caruthers SD, et al. Endothelial alpha(v) beta3 integrin-targeted fumagillin nanoparticles inhibit angiogenesis in atherosclerosis. Arterioscler Thromb Vasc Biol. 2006;26(9): 2103-2109.

35. Nakashiro S, Matoba T, Umezu R, et al. Pioglitazone-incorporated nanoparticles prevent plaque destabilization and rupture by regulating monocyte/macrophage differentiation in ApoE-/- mice. Arterioscler Thromb Vasc Biol. 2016;36(3):491-500.

36. Tang J, Baxter S, Menon A, et al. Immune cell screening of a nanoparticle library improves atherosclerosis therapy. Proc Natl Acad Sci USA. 2016;113(44):E6731-E6740.

37. Peters D, Kastantin M, Kotamraju VR, et al. Targeting atherosclerosis by using modular, multifunctional micelles. Proc Natl Acad Sci US A. 2009;106(24):9815-9819.

38. Kamaly N, Fredman G, Subramanian M, et al. Development and in vivo efficacy of targeted polymeric inflammation-resolving nanoparticles. Proc Natl Acad Sci U S A. 2013;110(16):6506-6511.

39. Cyrus T, Wickline SA, Lanza GM. Nanotechnology in interventional cardiology. Wiley Interdiscip Rev Nanomed Nanobiotechnol. 2012;4(1):82-95.
40. Nakano K, Egashira K, Masuda S, et al. Formulation of nanoparticle-eluting stents by a cationic electrodeposition coating technology: efficient nanodrug delivery via bioabsorbable polymeric nanoparticle-eluting stents in porcine coronary arteries. JACC Cardiovasc Interv. 2009;2(4):277-283.

41. Tsukie N, Nakano K, Matoba T, et al. Pitavastatin-incorporated nanoparticle-eluting stents attenuate in-stent stenosis without delayed endothelial healing effects in a porcine coronary artery model. $J$ Atheroscler Thromb. 2013;20(1):32-45.

42. Alam T, Khan S, Gaba B, Haider MF, Baboota S, Ali J. Nanocarriers as treatment modalities for hypertension. Drug Deliv. 2017;24(1):358-369.

43. Wright J, Musini V, Gill R. First-line drugs for hypertension. Cochrane Database Syst Rev. 2018;4:CD001841.

44. Sharma M, Sharma R, Jain DK. Nanotechnology based approaches for enhancing oral bioavailability of poorly water soluble antihypertensive drugs. Scientifica (Cairo). 2016;2016:8525679.

45. Gorain B, Choudhury H, Kundu A, et al. Nanoemulsion strategy for olmesartan medoxomil improves oral absorption and extended antihypertensive activity in hypertensive rats. Colloids Surf B Biointerfaces. 2014;115:286-294.

46. Singh B, Singh R, Bandyopadhyay S, Kapil R, Garg B. Optimized nanoemulsifying systems with enhanced bioavailability of carvedilol. Colloids Surf B Biointerfaces. 2013;101:465-474.

47. Qumbar M, Ameeduzzafar, Imam SS, Ali J, Ahmad J, Ali A. Formulation and optimization of lacidipine loaded niosomal gel for transdermal delivery: in-vitro characterization and in-vivo activity. Biomed Pharmacother. 2017;93:255-266.

48. Ahad A, Aqil M, Kohli K, Sultana Y, Mujeeb M. Nano vesicular lipid carriers of angiotensin II receptor blocker: Anti-hypertensive and skin toxicity study in focus. Artif Cells Nanomed Biotechnol. 2016;44(3):1002-1007.

49. Shafiq S, Shakeel F, Talegaonkar S, Ahmad FJ, Khar RK, Ali M. Development and bioavailability assessment of ramipril nanoemulsion formulation. Eur J Pharm Biopharm. 2007;66(2):227-243.

50. Chhabra G, Chuttani K, Mishra AK, Pathak K. Design and development of nanoemulsion drug delivery system of amlodipine besilate for improvement of oral bioavailability. Drug Dev Ind Pharm. 2011;37(8):907-916.

51. Elkasabgy NA, Elsayed I, Elshafeey AH. Design of lipotomes as a novel dual functioning nanocarrier for bioavailability enhancement of lacidipine: in-vitro and in-vivo characterization. Int J Pharm. 2014;472(1-2):369-379.

52. Shah U, Joshi G, Sawant K. Improvement in antihypertensive and antianginal effects of felodipine by enhanced absorption from PLGA nanoparticles optimized by factorial design. Mater Sci Eng C Mater Biol Appl. 2014;35:153-163.

53. Niaz T, Shabbir S, Manzoor S, et al. Antihypertensive nano-ceuticales based on chitosan biopolymer: physico-chemical evaluation and release kinetics. Carbohydr Polym. 2016;142:268-274.

54. Dudhipala N, Veerabrahma K. Pharmacokinetic and pharmacodynamic studies of nisoldipine-loaded solid lipid nanoparticles developed by central composite design. Drug Dev Ind Pharm. 2015;41(12):1968-1977.

55. Ranpise NS, Korabu SS, Ghodake VN. Second generation lipid nanoparticles (NLC) as an oral drug carrier for delivery of lercanidipine hydrochloride. Colloids Surf B Biointerfaces. 2014;116:81-87.

56. Cabrales P, Han G, Roche C, Nacharaju P, Friedman AJ, Friedman JM. Sustained release nitric oxide from long-lived circulating nanoparticles. Free Radic Biol Med. 2010;49(4):530-538.

57. Ghasemian E, Motaghian P, Vatanara A. D-optimal design for preparation and optimization of fast dissolving bosentan nanosuspension. $A d v$ Pharm Bull. 2016;6(2):211-218.

58. Nakamura K, Matsubara H, Akagi S, et al. Nanoparticle-mediated drug delivery system for pulmonary arterial hypertension. J Clin Med. 2017;6(5):48.

59. Akagi S, Nakamura K, Matsubara H, et al. Intratracheal administration of prostacyclin analogue-incorporated nanoparticles ameliorates the development of monocrotaline and sugen-hypoxia-induced pulmonary arterial hypertension. J Cardiovasc Pharmacol. 2016;67(4):290-298. 
60. Akagi S, Nakamura K, Miura D, et al. Delivery of imatinib-incorporated nanoparticles into lungs suppresses the development of monocrotaline-induced pulmonary arterial hypertension. Int Heart J. 2015; 56(3):354-359.

61. Gupta V, Gupta N, Shaik IH, et al. Liposomal fasudil, a rho-kinase inhibitor, for prolonged pulmonary preferential vasodilation in pulmonary arterial hypertension. J Control Release. 2013;167(2):189-199.

62. Chen L, Nakano K, Kimura S, et al. Nanoparticle-mediated delivery of pitavastatin into lungs ameliorates the development and induces regression of monocrotaline-induced pulmonary artery hypertension. Hypertension. 2011;57(2):343-350.

63. Kimura S, Egashira K, Chen L, et al. Nanoparticle-mediated delivery of nuclear factor kappaB decoy into lungs ameliorates monocrotaline-induced pulmonary arterial hypertension. Hypertension. 2009;53(5):877-883.

64. Yongjun Q, Huanzhang S, Wenxia Z, Hong T, Xijun X. From changes in local RAAS to structural remodeling of the left atrium: a beautiful cycle in atrial fibrillation. Herz. 2015;40(3):514-520.

65. Yu L, Scherlag BJ, Dormer K, et al. Autonomic denervation with magnetic nanoparticles. Circulation. 2010;122(25):2653-2659.

66. Lu Z, Scherlag BJ, Lin J, et al. Autonomic mechanism for initiation of rapid firing from atria and pulmonary veins: evidence by ablation of ganglionated plexi. Cardiovasc Res. 2009;84(2):245-252.

67. Madigan M, Atoui R. Therapeutic use of stem cells for myocardial infarction. Bioengineering. 2018;5(2):E28.

68. Ding Z, Temme S, Quast C, et al. Epicardium-derived cells formed after myocardial injury display phagocytic activity permitting in vivo labeling and tracking. Stem Cells Transl Med. 2016;5(5):639-650.

69. Zhu K, Li J, Wang Y, Lai H, Wang C. Nanoparticles-assisted stem cell therapy for ischemic heart disease. Stem Cells Int. 2016: 1384658 .

70. Binsalamah ZM, Paul A, Khan AA, Prakash S, Shum-Tim D. Intramyocardial sustained delivery of placental growth factor using nanoparticles as a vehicle for delivery in the rat infarct model. Int $J$ Nanomedicine. 2011;6:2667-2678.

71. Nakano Y, Matoba T, Tokutome M, et al. Nanoparticle-mediated delivery of irbesartan induces cardioprotection from myocardial ischemiareperfusion injury by antagonizing monocyte-mediated inflammation. Sci Rep. 2016;6(1):29601.

72. Galagudza M, Korolev D, Postnov V, et al. Passive targeting of ischemic-reperfused myocardium with adenosine-loaded silica nanoparticles. Int J Nanomedicine. 2012;7:1671-1678.

73. Harel-Adar T, Ben Mordechai T, Amsalem Y, Feinberg MS, Leor J, Cohen S. Modulation of cardiac macrophages by phosphatidylserinepresenting liposomes improves infarct repair. Proc Natl Acad Sci USA. 2011;108(5):1827-1832.

74. Vani JR, Mohammadi MT, Foroshani MS, Jafari M. Polyhydroxylated fullerene nanoparticles attenuate brain infarction and oxidative stress in rat model of ischemic stroke. EXCLI J. 2016;15:378-390.

75. Panagiotou S, Saha S. Therapeutic benefits of nanoparticles in stroke. Front Neurosci. 2015;9(22):182.

76. Thompson BJ, Ronaldson PT. Drug delivery to the ischemic brain. $A d v$ Pharmacol. 2014;71:165-202.

77. Torchilin VP. Multifunctional, stimuli-sensitive nanoparticulate systems for drug delivery. Nat Rev Drug Discov. 2014;13(11):813-827.

78. Chaudhary MA, Guo LW, Shi X, et al. Periadventitial drug delivery for the prevention of intimal hyperplasia following open surgery. J Control Release. 2016;233:174-180.

79. Amezcua R, Shirolkar A, Fraze C, Stout DA. Nanomaterials for cardiac myocyte tissue engineering. Nanomaterials. 2016;6(7):E133.

80. Hashimoto H, Olson EN, Bassel-Duby R. Therapeutic approaches for cardiac regeneration and repair. Nat Rev Cardiol. Epub 2018 Jun 5.

81. Bouten CV, Dankers PY, Driessen-Mol A, Pedron S, Brizard AM, Baaijens FP. Substrates for cardiovascular tissue engineering. Adv Drug Deliv Rev. 2011;63(4-5):221-241.

82. Dimmeler S, Burchfield J, Zeiher AM. Cell-based therapy of myocardial infarction. Arterioscler Thromb Vasc Biol. 2008;28(2):208-216.
83. Lozano O, Torres-Quintanilla A, García-Rivas G. Nanomedicine for the cardiac myocyte: where are we? J Control Release. 2018; 271:149-165.

84. Ye KY, Black LD. Strategies for tissue engineering cardiac constructs to affect functional repair following myocardial infarction. J Cardiovasc Transl Res. 2011;4(5):575-591.

85. Kim D-H, Kim P, Song I, et al. Guided three-dimensional growth of functional cardiomyocytes on polyethylene glycol nanostructures. Langmuir. 2006;22(12):5419-5426.

86. Kim DH, Lipke EA, Kim P, et al. Nanoscale cues regulate the structure and function of macroscopic cardiac tissue constructs. Proc Natl Acad Sci US A. 2010;107(2):565-570.

87. Aghdam RM, Shakhesi S, Najarian S, Mohammadi MM, Ahmadi Tafti SH, Mirzadeh H. Fabrication of a nanofibrous scaffold for the in vitro culture of cardiac progenitor cells for myocardial regeneration. Int J Polym Mater Polym Biomater. 2014;63(5):229-239.

88. Simón-Yarza T, Rossi A, Heffels KH, Prósper F, Groll J, BlancoPrieto MJ. Polymeric electrospun scaffolds: neuregulin encapsulation and biocompatibility studies in a model of myocardial ischemia. Tissue Eng Part A. 2015;21(9-10):1654-1661.

89. Kai D, Prabhakaran M, Jin G, Ramakrishna S. Polypyrrole-contained electrospun conductive nanofibrous membranes for cardiac tissue engineering. J Biomed Mater Res A. 2011;99(3):376-385.

90. Martinelli V, Cellot G, Toma FM, et al. Carbon nanotubes promote growth and spontaneous electrical activity in cultured cardiac myocytes. Nano Lett. 2012;12(4):1831-1838.

91. Shin SR, Jung SM, Zalabany M, et al. Carbon-nanotube-embedded hydrogel sheets for engineering cardiac constructs and bioactuators. ACS Nano. 2013;7(3):2369-2380.

92. Zhou J, Chen J, Sun H, et al. Engineering the heart: evaluation of conductive nanomaterials for improving implant integration and cardiac function. Sci Rep. 2015;4(1):3733.

93. Ravichandran R, Venugopal JR, Sundarrajan S, Mukherjee S, Sridhar R, Ramakrishna S. Minimally invasive injectable short nanofibers of poly(glycerol sebacate) for cardiac tissue engineering. Nanotechnology. 2012;23(38):385102.

94. Dvir T, Timko BP, Brigham MD, et al. Nanowired three-dimensional cardiac patches. Nat Nanotechnol. 2011;6(11):720-725.

95. Stout DA, Yoo J, Santiago-Miranda AN, Webster TJ. Mechanisms of greater cardiomyocyte functions on conductive nanoengineered composites for cardiovascular application. Int J Nanomedicine. 2012;7: 5653-5669.

96. Malki M, Fleischer S, Shapira A, Dvir T. Gold nanorod-based engineered cardiac patch for suture-free engraftment by near IR. Nano Lett. 2018;18(7):4069-4073.

97. Lin YD, Yeh ML, Yang YJ, et al. Intramyocardial peptide nanofiber injection improves postinfarction ventricular remodeling and efficacy of bone marrow cell therapy in pigs. Circulation. 2010;122(11 Suppl): S132-S141.

98. Singelyn JM, Dequach JA, Seif-Naraghi SB, Littlefield RB, SchupMagoffin PJ, Christman KL. Naturally derived myocardial matrix as an injectable scaffold for cardiac tissue engineering. Biomaterials. 2009;30(29):5409-5416.

99. Wang H, Liu Z, Li D, et al. Injectable biodegradable hydrogels for embryonic stem cell transplantation: improved cardiac remodelling and function of myocardial infarction. J Cell Mol Med. 2012;16(6): 1310-1320.

100. Paul A, Hasan A, Kindi HA, et al. Injectable graphene oxide/hydrogelbased angiogenic gene delivery system for vasculogenesis and cardiac repair. ACS Nano. 2014;8(8):8050-8062.

101. Nguyen MM, Gianneschi NC, Christman KL. Developing injectable nanomaterials to repair the heart. Curr Opin Biotechnol. 2015;34: 225-231.

102. Evans BC, Hocking KM, Osgood MJ, et al. MK2 inhibitory peptide delivered in nanopolyplexes prevents vascular graft intimal hyperplasia. Sci Transl Med. 2015;7(291):ra295. 
103. Wolf K, Alexander S, Schacht V, et al. Collagen-based cell migration models in vitro and in vivo. Semin Cell Dev Biol. 2009; 20(8):931-941.

104. Li H, Chai S, Dai L, Gu C. Collagen external scaffolds mitigate intimal hyperplasia and improve remodeling of vein grafts in a rabbit arteriovenous graft model. Biomed Res Int. 2017;2017:7473437.

105. Boire TC, Balikov DA, Lee Y, Guth CM, Cheung-Flynn J, Sung HJ. Biomaterial-based approaches to address vein graft and hemodialysis access failures. Macromol Rapid Commun. 2016;37(23):1860-1880.

106. Robinson E, Kaushal S, Alaboson J, et al. Combinatorial release of dexamethasone and amiodarone from a nano-structured parylene-C film to reduce perioperative inflammation and atrial fibrillation. Nanoscale. 2016;8(7):4267-4275.

107. Autorino R, Kaouk JH, Stolzenburg JU, et al. Current status and future directions of robotic single-site surgery: a systematic review. Eur Urol. 2013;63(2):266-280.

108. Nakadate R, Arata J, Hashizume M. Next-generation robotic surgeryfrom the aspect of surgical robots developed by industry. Minim Invasive Ther Allied Technol. 2015;24(1):2-7.

109. Burkhardt JD, Natale A. New technologies in atrial fibrillation ablation. Circulation. 2009;120(15):1533-1541.

110. Pennington DG. The impact of new technology on cardiothoracic surgical practice. Ann Thorac Surg. 2006;81(1):10-18.

111. Da Costa A, Guichard JB, Maillard N, Romeyer-Bouchard C, Gerbay A, Isaaz K. Substantial superiority of Niobe ES over Niobe II system in remote-controlled magnetic pulmonary vein isolation. Int J Cardiol. 2017;230:319-323

112. Shurrab M, Danon A, Lashevsky I, et al. Robotically assisted ablation of atrial fibrillation: a systematic review and meta-analysis. Int $J$ Cardiol. 2013;169(3):157-165.

113. Gonzalez JE, Nguyen DT. Supraventricular tachycardia in a patient with an interrupted inferior vena cava. Card Electrophysiol Clin. 2016;8(1):45-50.

114. Liu XY, Jacobsen PK, Pehrson S, Chen X. Catheter ablation of incisional atrial tachycardia using remote magnetic navigation in patients after heart surgery: comparison between acquired and congenital heart disease. Europace. 2018;20(Suppl 2):ii33-ii39.

115. Qian P, De Silva K, Kumar S, et al. Early and long-term outcomes after manual and remote magnetic navigation-guided catheter ablation for ventricular tachycardia. Europace. 2018;20(Suppl 2):ii11-ii21.

116. Grodanz E. Robotic mitral valve repair. J Cardiovasc Nurs. 2015;30(4): 325-331.

117. Algarni KD, Suri RM, Daly RC. Robotic-assisted mitral valve repair: surgical technique. Multimed Man Cardiothorac Surg. 2014:pii $\mathrm{mmu} 022$.

118. Kuo CC, Hsing $\mathrm{CH}$, Chen CI, Lee CH, Cheng BC. Robotic totally endoscopic coronary artery bypass for isolated ostial stenosis of the left coronary artery. J Thorac Dis. 2017;9(12):E1060-E1063.

119. Smitson CC, Ang L, Pourdjabbar A, Reeves R, Patel M, Mahmud E. Safety and feasibility of a novel, second-generation robotic-assisted system for percutaneous coronary intervention: first-in-human report. J Invasive Cardiol. 2018;30(4):152-156.

120. Khalpey Z, Korovin L, Chitwood WR, Poston R. Robot-assisted septal myectomy for hypertrophic cardiomyopathy with left ventricular outflow tract obstruction. J Thorac Cardiovasc Surg. 2014; 147(5):1708-1709.

121. Tuna EE, Franke TJ, Bebek O, Shiose A, Fukamachi K, Cavuşoğlu MC. Heart motion prediction based on adaptive estimation algorithms for robotic assisted beating heart surgery. IEEE Trans Robot. 2013; 29(1):261-276.
122. Chang KD, Raheem AA, Rha KH. Novel robotic systems and future directions. Indian J Urol. 2018;34(2):110-114.

123. Simon-Yarza T, Bataille I, Letourneur D. Cardiovascular bioengineering: current state of the art. J Cardiovasc Transl Res. 2017; 10(2):180-193.

124. Srinivasan R, Marchant RE, Gupta AS. In vitro and in vivo platelet targeting by cyclic RGD-modified liposomes. J Biomed Mater Res A. 2010;93(3):1004-1015.

125. Gutman D, Golomb G. Liposomal alendronate for the treatment of restenosis. J Control Release. 2012;161(2):619-627.

126. Hofmeister LH, Lee SH, Norlander AE, et al. Phage-displayguided nanocarrier targeting to atheroprone vasculature. ACS Nano. 2015;9(4):4435-4446.

127. Lipinski MJ, Amirbekian V, Frias JC, et al. MRI to detect atherosclerosis with gadolinium-containing immunomicelles targeting the macrophage scavenger receptor. Magn Reson Med. 2006;56(3): 601-610

128. Chan JM, Rhee JW, Drum CL, et al. In vivo prevention of arterial restenosis with paclitaxel-encapsulated targeted lipid-polymeric nanoparticles. Proc Natl Acad Sci U S A. 2011;108(48):19347-19352.

129. Cohen-Sela E, Chorny M, Koroukhov N, Danenberg HD, Golomb G. A new double emulsion solvent diffusion technique for encapsulating hydrophilic molecules in PLGA nanoparticles. J Control Release. 2009;133(2):90-95.

130. Nguyen TH, Bryant H, Shapsa A, et al. Manganese G8 dendrimers targeted to oxidation-specific epitopes: in vivo MR imaging of atherosclerosis. J Magn Reson Imaging. 2015;41(3):797-805.

131. Liu J, Gu C, Cabigas EB, et al. Functionalized dendrimer-based delivery of angiotensin type 1 receptor siRNA for preserving cardiac function following infarction. Biomaterials. 2013;34(14): 3729-3736.

132. Reddy MK, Vasir JK, Sahoo SK, Jain TK, Yallapu MM, Labhasetwar V. Inhibition of apoptosis through localized delivery of rapamycinloaded nanoparticles prevented neointimal hyperplasia and reendothelialized injured artery. Circ Cardiovasc Interv. 2008;1(3): 209-216.

133. Zohra FT, Medved M, Lazareva N, Polyak B. Functional behavior and gene expression of magnetic nanoparticle-loaded primary endothelial cells for targeting vascular stents. Nanomedicine. 2015;10(9): 1391-1406.

134. Chorny M, Fishbein I, Yellen BB, et al. Targeting stents with local delivery of paclitaxel-loaded magnetic nanoparticles using uniform fields. Proc Natl Acad Sci U S A. 2010;107(18):8346-8351.

135. Cho BH, Park JR, Nakamura MT, Odintsov BM, Wallig MA, Chung BH. Synthetic dimyristoylphosphatidylcholine liposomes assimilating into high-density lipoprotein promote regression of atherosclerotic lesions in cholesterol-fed rabbits. Exp Biol Med. 2010; 235(10):1194-1203.

136. Myerson J, He L, Lanza G, Tollefsen D, Wickline S. Thrombininhibiting perfluorocarbon nanoparticles provide a novel strategy for the treatment and magnetic resonance imaging of acute thrombosis. J Thromb Haemost. 2011;9(7):1292-1300.

137. Stein-Merlob AF, Hara T, McCarthy JR, et al. Atheroma susceptible to thrombosis exhibit impaired endothelial permeability in vivo as assessed by nanoparticle-based fluorescence molecular imaging. Circ Cardiovasc Imaging. 2017;10(5):e005813.

138. Zhao J, Mo Z, Guo F, Shi D, Han QQ, Liu Q. Drug loaded nanoparticle coating on totally bioresorbable PLLA stents to prevent in-stent restenosis. J Biomed Mater Res B Appl Biomater. 2018;106(1): 88-95. 


\section{Publish your work in this journal}

The International Journal of Nanomedicine is an international, peerreviewed journal focusing on the application of nanotechnology in diagnostics, therapeutics, and drug delivery systems throughout the biomedical field. This journal is indexed on PubMed Central, MedLine, CAS, SciSearch $\AA$, Current Contents $\AA /$ Clinical Medicine,

Journal Citation Reports/Science Edition, EMBase, Scopus and the Elsevier Bibliographic databases. The manuscript management system is completely online and includes a very quick and fair peer-review system, which is all easy to use. Visit http://www.dovepress.com/ testimonials.php to read real quotes from published authors.

Submit your manuscript here: http://www.dovepress.com/international-journal-of-nanomedicine-journal 